\title{
Effect of Religiosity and Spirituality on Employees Prosocial Behavior With the Mediatory Role of Humanism and Ethics
}

\author{
Aneeqa Wasim \\ Karachi University Business School, University of Karachi, Karachi, Pakistan \\ E-mail: aniqaw@ymail.com \\ Danish Ahmed Siddiqui \\ Karachi University Business School, University of Karachi, Karachi, Pakistan \\ E-mail: daanish79@hotmail.com
}

Received: November 4, 2020 Accepted: December 4, 2020 Published: December 7, 2020

doi:10.5296/ijsw.v7i2.17796 URL: https://doi.org/10.5296/ijsw.v7i2.17796

\begin{abstract}
Purpose - People belongs to different religious groups found prosocial with each other instead of having different religious beliefs and practices, but the reason is less known about why it is so. This paper aims to answer this question by proposing a theoretical framework, hypothesizing that religiosity inculcates the spirit of humanism and ethics, that would turn individual into prosocial, religiosity also tends to make people more spiritual, in turn, make them more humane and ethical.

Design \methodology - A well-structured framework is developed, and the PLS-SEM two-step approach is used to generate results by using SmartPLS3. Data is collected through the primary data collection technique and a survey based on 1000 questionnaires is conducted out of which 356 responses were received.

Findings - The empirical result shows that religiosity has a significant positive impact on prosocial behavior directly, as well as through Humanism and ethics. Whereas spirituality has an insignificant impact on prosocial behavior directly but has an indirect effect through both humanism and ethics. It is also found that religiosity also has a significant impact on spirituality.
\end{abstract}


Limitations - Data is limited to upper and middle-level employees of well-performing organizations of Karachi.

Keywords: Religiosity, Spirituality, Humanism, Ethics, Prosocial-behavior

\section{Introduction}

Prosocial behavior is the intention to help others, feeling empathy, and behaving in a way to do something that benefited others (Eisenberg \& Mussen, 1989). Many factors enforce the prosocial behavior of peoples including the increasing trend of poverty and unemployment because of the concern and feeling of other people's rights and welfare. It is challenging for many social scientists to understand why people being a stranger act in a way to help others that are beneficial to them but costly to the individual in action. Many reasons are still not fully focused. The main reasons may include the intension to gain the reciprocal benefit or to create a good self-image in public or altruistic reasons which is due to the phycological factor that includes persons' mental health, religious views and the share \& care childhood training given by parents that are included in this study. Good mental health reflected by good ethics similarly the humanity is shown by share \& care attitude. The reason for this analysis is to establish the relation between religiosity and spirituality and how it impacts prosocial behaviors. Religiosity and spirituality are the most important and deep part of a persons' life based on which their act depends on whether the person holds strong knowledge or not, their acts define the extent of their religious and spiritual views. Spirituality is something that provides the purpose of living to people within the community (Ashmos \& Duchon, 2000) while religiosity is related to longer life and better psychological and physical stability (Zimmer et al., 2016). Another factor that is ethics and humanism, taken as a mediator to test whether it plays a role while going toward social work. All these factors have a direct impact on human thinking that is reflected by their acts because every religion taught to help the less privileged ones an earlier survey suggests that spiritual people were more than twice likely in giving services than unspiritual people (Wuthnow, 1994). Other researchers have found that religion is strongly associated with planned helping (Omoto, Snyder, \& Berghuis, 1993) as when people considering helping out in organ transplantation or surgery or other types of volunteer service they get phycological well-being (Krause \& Hayward, 2014).

In Pakistan people seems to be highly involved in social activities especially in the religious months e.g. Ramadan, even having low incomes. Here a problem arises whether it is just because of religion and only people belongs to the same religion help and care for each other. This sort of thinking is a part of many countries no matter which religion they have. Although the question received while doing the survey witnesses this problem as many people before filling the questionnaire asked the reason for this research because they believe, the social activity, helping, and caring for other people is just because of the same religion. In reality, there are many other factors due to which pro-sociality initiates that is also reflected by the responses received from those peoples.

Many people who are not so religious can deeply involve in social activity similarly people from different religions show love and care for each other. Therefore, it becomes necessary to think about what is the other things that stimulate pro-sociality in individuals. 
This study plays a role in adding substance to the linkage between religiosity and spirituality and its impact on prosocial behavior to the literature. This study is required to contribute to researchers and to determine the prosocial behavior of the people effectively. The practitioners should know that spirituality is not always related to religious beliefs and more research is required on spiritual matters (Fry, 2003). An organization needs to become informed that spirituality can be used in the workplace but religion must be distinguished from spirituality so that harmony in the workplace will be insured.

The expected findings could be if the initiation to assimilate spirituality into religious people is taken, the quality of selflessness and prosocial behavior can increase which might have a long-lasting effect on the economy.

\subsection{Research Questions}

The main postulates of this research are presented as:

- Does the level of religious belief influences the prosocial behaviors of a human being?

- Does the level of spirituality influence the prosocial behaviors of a human being?

- Is there any relation between religiosity and spirituality?

- Do ethics and humanism mediate the role of religiosity and prosocial behaviors?

- Do ethics and humanism mediate the role of spirituality and prosocial behaviors?

\section{Literature Review}

The behavior has been defined as "the sum of the social psyche that includes impulses, motivation, wishes, drives, instincts, and cravings as expressed by a persons' behavior or motor activity" (Parrish, 2014). It has been seen that mostly lower-class individuals are found to be more prosocial than the upper class because of their greater commitment to equalitarian views and feelings of compassion (Piff et al, 2010). However, acting prosocially, the role of personality has a strong impact on individuals' life (Kline et al, 2017) investigate the impact of personality on prosocial behavior by multi-level meta-analysis (MLMA) method and found that agreeableness and openness of big five traits have a significant impact. The main thing that motivates prosocial behavior is the fundamental personal need of living a meaningful life, therefore (Klein, N., 2017). According to (Raposa et al., 2015) prosocial behavior can be an effective strategy for reducing the negative impact of stress in life. Apart from internal factors some external factors also play an important role in influencing the prosociality in individuals one of them is the peers' effect, positive support from peers can enhance the social attitude in workplaces (Hoorn et al, 2014). Most of the time certain events strongly hits the behavior of individuals that remained the worse time they had personally gone through or faced by their relatives and close friends, in that moment people wilfully present themselves for the person suffering the same situation they had before and try to help them out as much they can. According to (Small \& Simonsohn, 2007) study, the psychological factor has also a strong influence on human behavior but above all the concept of God and the belief that every act of all individuals is watching by the supernatural power (God) is the biggest reason to behave in a manner that benefits others (Shariff \& Norenzayan, 2007). According to (Marsh, 2007) self-identification of needy people is a better predictor of prosocial behavior in individuals than empathy gender and mood, therefore, the more the needy people identified accurately the more the prosocial behavior. Similarly, when these 
individuals see the expression of gratitude for their effort they feel socially valued (Grant \& Gino, 2010). This feeling of being worth by people motivate their prosocial behavior further in their life.

Osman-Gani et al. (2013) analyze that better spiritual conditions enhance employees' performance while religiosity moderates the effect of spirituality in employees' job performance. Einolf, C. J. (2013) states daily spiritual experience significantly predicts charitable activity volunteering and helping individual personally knows but doesn't affect by religion difference. Religiosity without spirituality may become harmful to prosocial activity (Li \& Chow, 2015).

(Ahmed \& Salas, 2008) examine how the internal effect of religious concepts affects kindness and corporation. Many researchers have analyzed the connection between religious participation and pro-sociality (Saroglou, 2013) but miss experimental assessments analyzing the particular inquiry regarding why taking part in religious assistance is connected to pro-sociality. An assumption presented by (Malhotra, 2010) and (Preston et al., 2013) recommends that going to religious assistance may work as provisional priming of religion, which has been appeared to initiate, somewhat, pro-sociality, particularly among devotees. Usually, the participation of religious services could along these lines be identified with some degree to pro-sociality because of redundant religious preparing or preparing of religious psychology.

However, their focus was limited to functional aspects and its effect on pro-sociality, how these functions make people pro-social was still left unexplored. In this regard, we proposed a theoretical framework, hypothesizing that religiosity inculcates the spirit of humanism and ethics, that would turn individual into prosocial, religiosity also tends to make people more spiritual, in turn, make them more humane and ethical. Hence, we investigated the impact of religiosity and spirituality on pro-social behavior keeping humanism and ethics as a mediating variable. Also, the link between religiosity and spirituality is established in this paper.

Hence, this is a novel attempt as far as the knowledge of the researcher no such research has been done till now that establishes the connection between the selected variables in this study i.e; spirituality, religiosity prosocial behavior, and humanism \& ethics as mediators. Moreover, no such study was conducted on Pakistani employees. This arouses the need for examining to interpret the relationship between all these factors and find their importance resulting in prosocial behavior.

\subsection{Theoretical Framework}

\subsubsection{Religiosity}

A religiosity is a group of behavior and customs full of different accepted assumptions along with standards that serve to give value to mortal presence. It illustrates an individual's acknowledgment and commitment to the standards and principles of religion (Park, 2000).

Religion promotes morality societal association (Patel \& Selvaraj, 2015). Religiosity strongly impacts leaders' social resultant activity (Verma \& Singh, 2016) the characteristics of religions are said to be noteworthy to the management of progressive organizations 
(Fernando, 2006). According to (Ghazzawi et al., 2016) religiously dedicated employees work hard, regard, and appreciate others, increase morale, devotion, and job satisfaction.

The psychological capacity of religious participation alludes to the comprehension of the significance of consecrated writings and the individual reflection it advances. It is for the most part conveyed through the readings and the lesson. Concerning support of sociality all the more explicitly, religious writings contain a lot of recommendations to deal with the powerless and those out of luck.

The enthusiastic capacity of religious participation alludes to the diverse positive feelings that emerged from religious assistance (Van Cappellen \& Rime, 2014). Previous exploration has demonstrated that the practice of religious beliefs advances positive feelings, for example, happiness, marvel, adoration, or harmony (Lambert et al., 2009). Despite the fact that these feelings are unquestionably not confined to the religious area and are evoked in mainstream settings as well, they seem, by all accounts, to be a continuous element of religious customs.

H1: Religiosity has a significant and positive effect on prosocial behavior

$\mathrm{H} 2$ : Religiosity has a significantly positive impact on humanism.

H3: Religiosity has a significantly positive impact on ethics.

\subsubsection{Relation Between Religiosity and Spirituality}

Researchers seem to have been less focused to examine religiousness and spiritual belief in their studies due to the difficulties of explaining and estimating the variable (King \& Crowther, 2004). Spirituality is said to be the backbone of religion and looking for holiness is the most central function of religion but the preceding examinations had shown the reality that religious belief and spiritual beliefs are not the same (King, 2007).

Maybe the difficult thing to accept in the procedure we have introduced here is the perception that religion is a wider construct than spirituality. However, most people perceive it in a reverse concept (Zinnbauer et al., 1997). It is also noted that there is a lesser distinction between religion and spirituality just as the greatest object of significance in life is purified. For individuals who locate the entire life holy have found little difference between religion and spirituality. Although it does not follow that the concept of religion should solely concentrate on spirituality. The other significant questions exist in our discipline for example I have already emphasized, we should also be focused on religious socialization that how an unsanctified end becomes dedicated to God or how secular objects got inspired with God's power. These such questions take us to concern on a wider side of religiosity apart from spirituality.

H4: Religiosity has a significantly positive impact on spirituality.

\subsubsection{Spirituality}

According to McCormick (1994), the word spirituality is explained as "the one's behavior being validated by an inner encounter a person has". It is a social presence of a persons' inherent mental scenes (Bhunia \& Mukhuti, 2011). (Salehzadeh et al. 2015) point out that holiness has a great positively noteworthy impact on behavior. (McLaughlin, 2009) suggests that at work spirituality concerns relating the persons' importance of dignity, continuity, and brilliance. Administrators who value spirituality as a necessary aspect of life reflect the lowest stress, greater humanity, and interconnectedness stakeholder groups and show a huge level of 
development and innovations (Shinde \& Fleck, 2015). The research of (Sharma et al. 2013) found that it tends to be recognized as an influencer of administrative effectiveness and efficiency.

Leadership and ethics have a combined relationship with spirituality as ethics are integral to leadership which guarantees ethics (Meng, 2016, p.411). The leaders' spiritual sides help them in deciding their moral choices. Lowery et al (2014), who discuss spirituality as a promising variable to concentrate comparable to ethics, discovered outcomes that show employees' recognitions about ethics at work are positively connected with their construct of individual spirituality.

H5: Spirituality has a significantly positive impact on prosocial behavior.

H6: Spirituality has a significantly positive impact on humanism.

H7: Spirituality has a significantly positive impact on ethics.

\subsubsection{Ethics}

Ethics is a systematic form of moral principle. Ethics is all about what is beneficial for people and society that also describe the moral philosophy. It helps to distinguish between right and wrong morally that helps in making a decision. People are not always found religiously ethical in many circumstances a group of people met who belong to different religious believes and values in different workplaces or institutes where they are required to be ethical for the sake of humanity so, the peace prevails that encourage the prosocial behavior in human being.

Work ethics in Islam and western economic tradition is conceptually different in Islam the Quran itself defines work ethics by the concept of halal \& haram and the concept of (al-'amal al-salih) which means that the work is good and beneficial to everyone and must be required to perform by everyone i.e. prosocial behavior. For every conduct, everyone will get the reward and punishment according to their conduct however Islam gives individuals the right to select the work according to their desire but this freedom is obligated to consider the need of society according to shariah (Possumah, Ismail, \& Shahimi, 2013). Therefore we can say that ethics has an important mediating role between religiosity, spirituality, and prosociality.

H8: Ethics has a significantly positive impact on prosocial behavior.

H9: Ethics has a significantly positive impact on humanism.

H10: Ethics mediates the influence of religiosity on prosocial behavior.

H11: Ethics mediates the influence of spirituality on prosocial behavior.

\subsubsection{Humanism}

Humanism theory focuses on internal and external stimuli as influencing, but the behavior of man doesn't determine because a man's will do not bound by anything but the perception of himself motivates him when he actively participates in the social process. Past observation reflects that humanism was not an outcome of eastern culture it comprises western culture (Xiaoming 2001). If we focus on Islamic culture it seems that humanism is integrated into religion in the name of "Brotherhood" which is strongly followed in Muslim society and is considered the part of belief in which sharing and helping the less privileged is obligatory to each Muslim brothers. (Usman et al., 2017) studies Islamic humanism and states that the role 


\section{Macrothink}

International Journal of Social Work

ISSN 2332-7278

2020, Vol. 7, No. 2

of Islamic education as a part of the national education system helps in developing human character is to foster the willingness to spread kindness and charity that cater happiness to mankind. (Horodecka \& Martowska, 2014) identified that individuals involved prosocially possess a higher level of emotional intelligence with the hope for success, unlike those individuals who have not been involved in any kind these actions that suggest that individuals are more likely to involve prosocially tends to represent the humanistic character of the man.

H12: Humanism has a significantly positive impact on prosocial behavior.

H13: Humanism mediates the influence of religiosity on prosocial behavior.

H14: Humanism mediates the influence of spirituality on prosocial behavior.

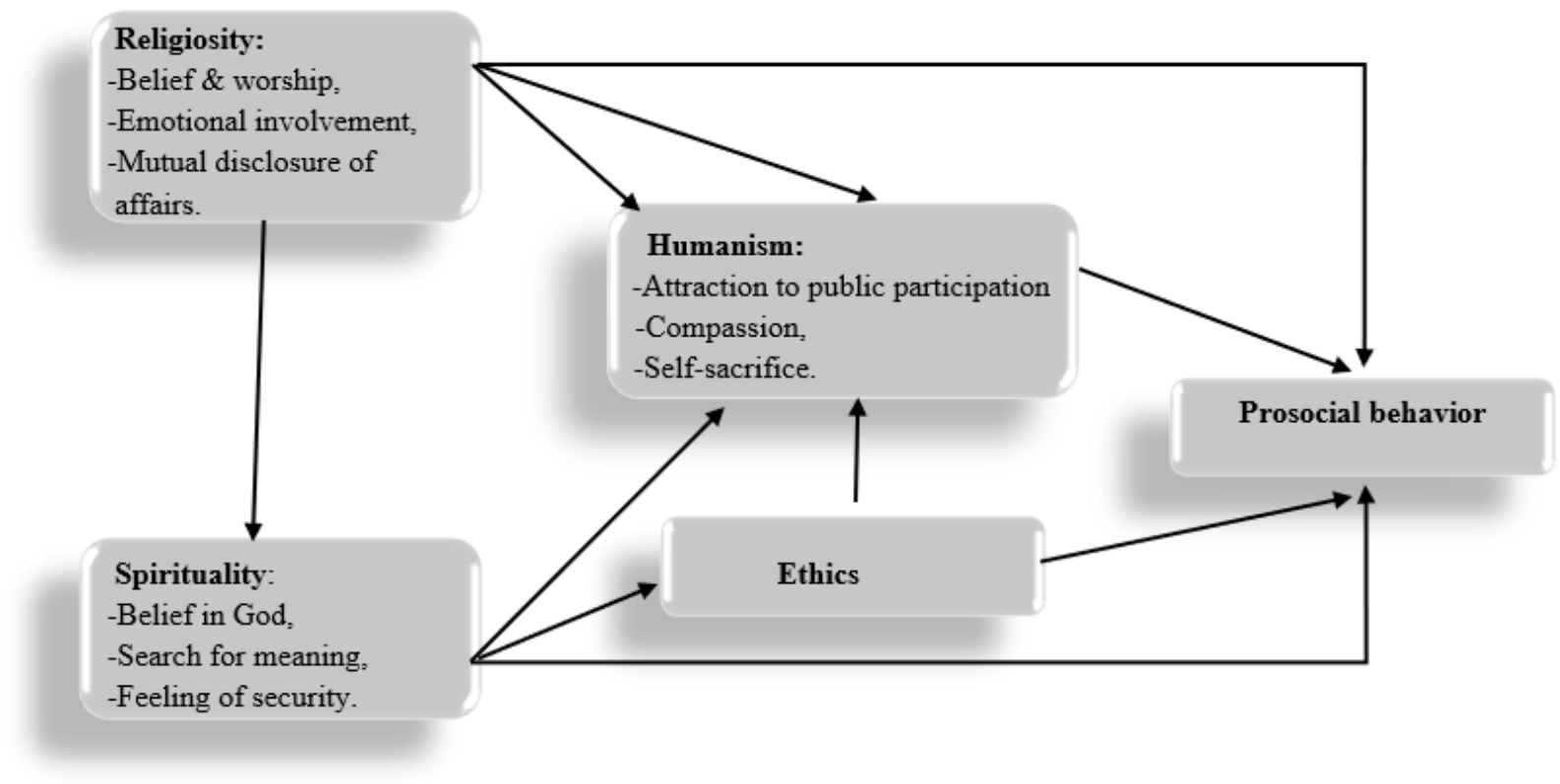

Source: self-made (2020)

\section{Research Methodology}

\subsection{Nature of Research}

The qualitative technique is used in this data collection process through a questionnaire. The questionnaire designed for this research targets middle and top-level employees.

\subsection{Population and Sample Size}

In this research sample size consist of 356 responses that are gathered from circulating 1000 questionnaire to the targeted recipients. Out of these 356 recipients, $25 \%$ are female and $75 \%$ are male. All the respondents belong to the middle and top-level management including managers, assistant managers, directors, assistant directors, CEOs, and team leaders, working in well-performing government and private organizations that are operating in different sectors of Pakistan. The majority of the contribution was received from the people age between 25 to 29 and very little contribution is recorded by the people age more than 35 . 


\section{Macrothink}

Therefore, this study comprises the perspective of people who were young and successful in their professional life age from 20 to 30 as shown below in the given chart.
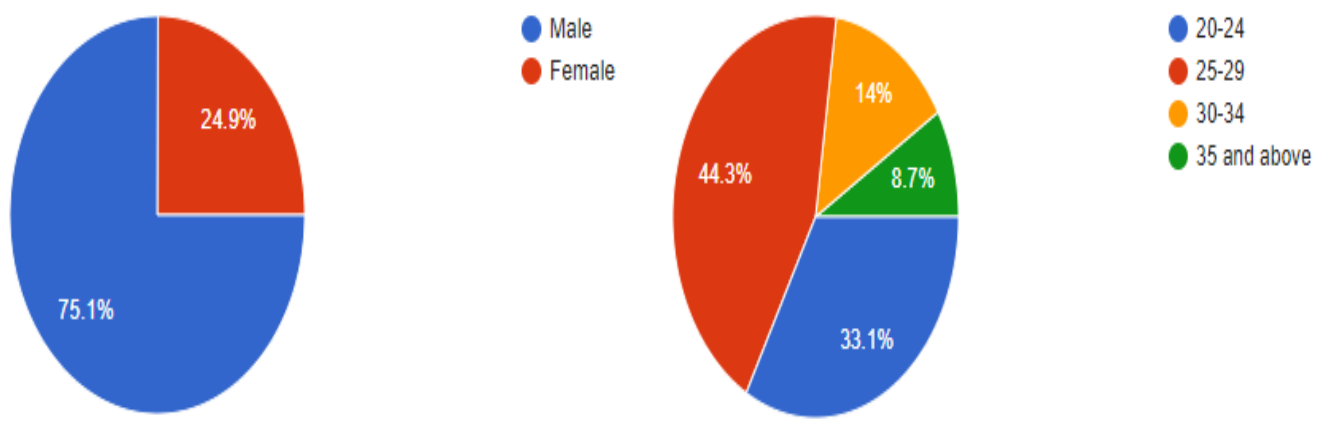

Figure 1. Descriptive statistics

\subsection{Instrument}

The questionnaire consists of two portions the first portion includes personal information regarding age, education, and designation and the second portion contains questions regarding the topic under the head of selected variables that are religiosity, spirituality, humanism, ethics, and prosocial behavior.

All the questions were answered on a 5-point Likert scale from strongly disagree to strongly agree i.e. from 1 to 5 . However, the first three questions of spirituality were answered from not at all important to most important, and the first questions of prosocial behavior were answered from daily giving charity to never i.e. from 1 to 5 .

Questionnaires include 60 questions and all questions are adopted from different sources. The questions of religiosity are adopted from (Joseph \& DiDuca, 2007) while the first four questions are self-developed. The questions of humanism are adopted from (Breaugh et al., 2017). The questions of prosocial behavior are adopted from a link of an online survey conducted by the researchers of the UK and Canada during the fall of 2010 to the summer of 2011. The questions of ethics and spirituality are adopted (Hardt et al, 2012).

\subsection{Variables}

In this study, five variables were included. Religiosity and spirituality were taken as independent variable humanism and ethics were taken as a mediating variable and prosocial behavior was taken as a dependent variable. Religiosity includes 12 question deals with three sub-variables (belief and worship - emotional involvement - mutual disclosure of affairs), spirituality includes 15 questions that deals with three sub-variables (belief in God - search for meaning - the feeling of security), humanism include 16 question deals with three sub-variables (attraction to public participation - compassion - self-sacrifice), ethics, and social work both include 7 questions. 
3.5 Data Integration Method and Statistical Procedure

The statistical procedure used in this study is partial least square and structural equation modeling (PLS-SEM) using SmartPLS3. Data is integrated by using a two-step approach in SmartPLS3. PLS- algorithm and bootstrapping test were calculated to generate results.

"According to (Garson, 2016) the two-step approach is the latent variable score (LVS) approach, based on the product of latent variable scores..."

\section{Data Analysis \& Results}

\subsection{Measurement of Outer Model}

The purpose behind the gauge of fit in the measurement model is to observe the reliability and validity of the measurement construct for which the test of convergent validity and discriminant validity was conducted by using the software SmartPLS3.

\subsection{Composite Reliability}

For assessing the reliability of indicators, it is suggested that the use of composite reliability is more authentic than Cronbach alpha's value. It is found that all the given values were exceeding the typically used level that is 0.70 according to (Hair et al., 2016) the accepted reliability value limit.

The result from Table 1 shows that all the values given in the table are greater than 0.8 that shows each measurement instrument is highly reliable and the outcomes from the questionnaire are stable for a similar targeted population and will generate the same result whenever the researcher reutilize the questionnaire at whatever point in time. It suggests that the occurring frequency of the survey assessment is higher.

\subsection{Convergent Validity}

Convergent validity assesses the extent to which measure correlates positively with the complementary measure of the same construct (Hair et al., 2016). Convergent validity is the level of agreement in two measures of the same variable (Carmines \& Zeller, 1979). According to (Fornell \& Larcker, 1981) when AVE value is higher than 0.5 convergent validity is formed and termed as effective for study while less than 0.5 is named as less effective for review. In the table given below, it is found that two variables AVE is less than 0.5 but its composite reliability Cronbach's alpha rho_A were found highly reliable therefore in this case we can accept variable having a value of AVE $<0.5$ if the composite reliability is $>0.6$ because the convergent validity of the construct is still adequate (Fornell \& Larcker, 1981).

Table 1. Construct-reliability-and-validity

\begin{tabular}{lllll}
\hline & $\begin{array}{l}\text { Cronbach's } \\
\text { Alpha }\end{array}$ & rho_A & $\begin{array}{l}\text { Composite } \\
\text { Reliability }\end{array}$ & $\begin{array}{l}\text { Average Variance } \\
\text { Extracted (AVE) }\end{array}$ \\
\hline attraction to public participation & 0.711 & 0.715 & 0.821 & 0.535 \\
belief \& worship & 0.702 & 0.750 & 0.803 & 0.508 \\
belief in god & 0.862 & 0.869 & 0.901 & 0.647 \\
compassion & 0.733 & 0.742 & 0.833 & 0.557 \\
\hline
\end{tabular}




\begin{tabular}{lllll}
\hline emotional involvement & 0.782 & 0.782 & 0.873 & 0.696 \\
ethics & 0.846 & 0.860 & 0.883 & 0.522 \\
feeling of security & 0.830 & 0.832 & 0.899 & 0.747 \\
humanism & 0.840 & 0.844 & 0.872 & 0.365 \\
mutual disclosure of affairs & 0.878 & 0.879 & 0.916 & 0.732 \\
religiosity & 0.901 & 0.924 & 0.919 & 0.520 \\
search for meaning & 0.857 & 0.857 & 0.897 & 0.636 \\
Self-sacrifice & 0.784 & 0.789 & 0.861 & 0.607 \\
social work & 0.756 & 0.775 & 0.836 & 0.508 \\
spirituality & 0.878 & 0.883 & 0.899 & 0.410 \\
\hline
\end{tabular}

\subsection{Discriminant Validity}

According to (Carmines \& Zeller, 1979) discriminant validity is defined as the differentiation of any individual construct from other constructs inside the model. Discriminant validity is assessed by Fornell and larcker criterion and the HTMT criterion here Fornell and larcker criterion is used. Discriminant validity is formed when factors which are in diagonal are significantly greater than those values that are off-diagonal in a parallel column and row i.e. the square root of AVE for all latent variables higher than the into construct correlations (Fornell \& Larcker, 1981). The table is given below fulfill Fornell and larcker except for some variable which was accepted based on significant loadings and convergent reliability as shown in the above tables. Variance inflation factor VIF was further analyzed to check their multicollinearity affect the approach by (Greene \& D'Arcy, 2010) and found all values lie within the critical region i.e less the 5 (Kock \& Lynn, 2012) hence found significant.

Table 2. Discriminant-validity and VIF

\begin{tabular}{|c|c|c|c|c|c|c|c|c|c|c|c|c|c|c|c|}
\hline & 1 & 2 & 3 & 4 & 5 & 6 & 7 & 8 & 9 & 10 & 11 & 12 & 13 & 14 & VIF \\
\hline attraction to public participation & 0.731 & & & & & & & & & & & & & & 1.649 \\
\hline belief \& worship & 0.132 & 0.713 & & & & & & & & & & & & & 1.925 \\
\hline belief in god & 0.422 & 0.464 & 0.804 & & & & & & & & & & & & 1.687 \\
\hline compassion & 0.577 & 0.088 & 0.427 & 0.746 & & & & & & & & & & & 1.743 \\
\hline emotional involvement & 0.233 & 0.656 & 0.522 & 0.184 & 0.834 & & & & & & & & & & 3.380 \\
\hline ethics & 0.341 & 0.284 & 0.342 & 0.361 & 0.282 & 0.722 & & & & & & & & & 1.399 \\
\hline feeling of security & 0.281 & 0.153 & 0.292 & 0.258 & 0.096 & 0.339 & 0.864 & & & & & & & & 1.267 \\
\hline Humanism & 0.808 & 0.181 & 0.497 & 0.834 & 0.218 & 0.471 & 0.390 & 0.604 & & & & & & & 1.846 \\
\hline mutual disclosure of affairs & 0.253 & 0.669 & 0.526 & 0.247 & 0.828 & 0.339 & 0.213 & 0.291 & 0.856 & & & & & & 3.487 \\
\hline
\end{tabular}




\begin{tabular}{|c|c|c|c|c|c|c|c|c|c|c|c|c|c|c|c|}
\hline religiosity & 0.240 & 0.820 & 0.558 & 0.209 & 0.919 & 0.342 & 0.182 & 0.268 & 0.953 & 0.721 & & & & & 1.347 \\
\hline search for meaning & 0.415 & 0.237 & 0.462 & 0.461 & 0.237 & 0.381 & 0.449 & 0.574 & 0.346 & 0.317 & 0.797 & & & & 1.482 \\
\hline Self-sacrifice & 0.393 & 0.211 & 0.352 & 0.444 & 0.112 & 0.430 & 0.398 & 0.771 & 0.204 & 0.198 & 0.504 & 0.779 & & & 1.589 \\
\hline social work & 0.437 & 0.312 & 0.311 & 0.354 & 0.298 & 0.551 & 0.255 & 0.496 & 0.340 & 0.354 & 0.374 & 0.402 & 0.713 & & \\
\hline spirituality & 0.493 & 0.385 & 0.793 & 0.514 & 0.397 & 0.453 & 0.644 & 0.641 & 0.487 & 0.479 & 0.862 & 0.538 & 0.412 & 0.640 & 2.090 \\
\hline
\end{tabular}

\subsection{The Structural Model (Inner Model) And Hypotheses Testing}

The structural model helps to understand and analyses the complex relations of the variables. The structural model was also tested and run on the SmartPLS 3.2.3 (Ringle, Wende, \& Becker, 2015). The structural model was run through bootstrapping (Haenlien \& Kaplan, 2004). The snapshot of the result after running the test is attached below along with the interpretation of the results.

In PLS-SEM, bootstrapping is one of the key strides, which gives the data of constancy of factor guesstimate. After running the bootstrap routine, Smart PLS shows the t-values for structural model estimates derived from the bootstrapping procedure. The results of path coefficients for all the hypotheses are shown in the following table. The t-value greater than $1.96(p<.005)$ shows that the relationship is significant at $95 \%$ confidence level $(\alpha=0.05)$. Paths showing whether the relationship between measured and latent variables are significant or not.

\subsubsection{Path Co-efficient}

Table 3. Path-coefficient

\begin{tabular}{lll}
\hline & Original Sample (O) & P Values \\
\hline Attraction to public participation -> humanism & 0.401 & 0.000 \\
Self-sacrifice -> humanism & 0.431 & 0.000 \\
Compassion -> humanism & 0.411 & 0.000 \\
Ethics -> Humanism & 0.241 & 0.001 \\
Religiosity -> Humanism & -0.090 & 0.121 \\
Spirituality -> Humanism & 0.575 & 0.000 \\
& & 0.000 \\
Belief in god -> spirituality & 0.474 & 0.000 \\
Feeling of security -> spirituality & 0.272 & 0.000 \\
Search for meaning -> spirituality & 0.521 & 0.000 \\
Religiosity -> Spirituality & 0.479 & 0.000 \\
\hline
\end{tabular}


Table 3 shows the path coefficient that represents the direct relationship between variables by original sample $(\mathrm{O})$ and $\mathrm{p}$-value shows the hypothesis acceptance criteria which is taken $10 \%$ in this research if the value is higher than 0.1 then the hypothesis should be rejected and if it is less than 0.1 then the hypothesis should be accepted.

Religiosity has an insignificant impact on humanism while a significant impact on ethics spirituality and prosocial behavior as indicated in the table above where p-values 0.121 is greater than 0.1 for humanism showing insignificance whereas for spirituality ethics and prosocial behavior p-values 0.000 and 0.080 and 0.049 respectively is less than 0.1 represent significance. Hence $\mathrm{H} 2$ is rejected whereas $\mathrm{H} 1 \mathrm{H} 3$ and $\mathrm{H} 4$ are accepted.

By analyzing the impact of the second independent variable spirituality we found that p-values for ethics and humanism is 0.000 and 0.001 less than 0.1 showing a significant impact of spirituality on ethics humanism while the insignificant impact on prosocial behavior as indicated by p-value 0.854 that is greater than 0.1 . Hence $\mathrm{H} 6$ and $\mathrm{H} 7$ are accepted and $\mathrm{H} 5$ is rejected.

Ethics is used as a mediator in our model, but it also affects directly humanism and prosocial behavior therefore it is important to check its significance level on these variables. The result shows that ethics has a significant effect on humanism and prosocial behavior as p-values reflect 0.001 and 0.000 less than 0.1 . Hence $\mathrm{H} 8$ and $\mathrm{H} 9$ are accepted.

Another mediator taken is humanism which has also a direct effect on prosocial behavior shows that $\mathrm{p}$-value 0.000 is less than 0.1 showing its significant impact on prosocial behavior Hence $\mathrm{H} 12$ is accepted.

The analysis of direct relation shown by the path coefficient of variables reflects that both mediators have a significant positive impact on dependent variable prosocial behavior that is the indication that it can mediate the impact of religiosity and spirituality pro-social behavior because the two independent variables have also a significant impact on mediators directly except the impact of religiosity on humanism that can affect prosocial behavior indirectly through mediators however for the correct figure we have to analyze the specific indirect effect. 


\subsubsection{Mediation Analysis}

In this step mediation analysis is carried out to examine the mediatory role of humanism and ethics on prosocial behavior. Table 4 shows the result that reflects the humanism has an insignificant mediating effect between religiosity and prosocial behavior while has a significant positive effect between spirituality and prosocial behavior as indicated by p-values 0.126 and 0.000 , respectively. Hence H13 is rejected and H14 is accepted.

Similarly, the ethics mediatory role also shows that there is an insignificant effect of ethics mediation between religiosity and prosocial behavior but has a significant positive effect between spirituality and prosocial behavior as shown by p-values 0.129 and 0.000 , respectively. Hence $\mathrm{H} 10$ is rejected and $\mathrm{H} 11$ is accepted.

Table 4. Specific-indirect-effect

\begin{tabular}{lll}
\hline & Original Sample (O) & P Values \\
\hline Religiosity -> Ethics -> prosocial behavior & 0.060 & 0.129 \\
Spirituality -> Ethics -> prosocial behavior & 0.138 & 0.000 \\
Religiosity -> Humanism -> prosocial behavior & -0.026 & 0.126 \\
Spirituality -> Humanism -> prosocial behavior & 0.167 & 0.000 \\
\hline
\end{tabular}

\section{Discussion}

The result of this study reflects that religiosity has a direct significant positive influence on prosocial behavior which is consistent to the research of (Oviedo, L. 2016) who argued that religion needs to be understood not like the necessity to generate pro-sociality to appear, survive, and develop but as emerging, serving and developing in a complex partnership with ethical manners and actions, while spirituality has an insignificant impact which is inconsistent with the study of (Einolf, C. J. 2013) that finds that daily spiritual experience significantly predicts the social activity like giving charity and helping to those individuals who are known personally by the helper therefore to identify spirituality and prosocial relation in unknown people we choose two mediators humanism and ethics and both mediators show significant impact on prosocial behavior directly. Its' also found that there is a significant relationship between independent variables and moderators except for the relation between religiosity and humanism.

The indirect effect was analyzed and the result shows that humanism and ethics both have a mediating effect between spirituality and prosocial behavior while both variables are found to have an insignificant mediating role between religiosity and prosocial behavior. It was also analyzed that - Is religiosity has an impact on spirituality? The result shows that there is a significant impact of religiosity on spirituality, which is similar to the finding of Osman-Gani et al. (2013) while contradicting the study of (Mirza, 2019). Religiosity and spirituality are considered similar by many people but most of them understand it in a reverse concept (Zinnbauer et al., 1997). The psychology of religion in terms of differentiation says religion is a 
broader construct it encircles the finding of many objects of considerations while spirituality only focuses on the specific object of significance i.e. the holiness. But it is also noted that there is a lesser distinction between religion and spirituality just as the greatest object of significance in life is purified. (Zwingmann et al., 2011) points out that this distinction between religiosity and spirituality is important in secular countries where people found themselves spiritual but not religious. This differentiation helps to promote prosocial behavior in the secular environment.

The study represents that the religious belief of people directly affects their social activity strongly and they actively participate in mentoring less privileged ones no matters from which religion that people belong the influential thing is their spiritual satisfaction that they get in serving the need of society. The main thing due to which people get spiritual satisfaction in doing prosocial behavior is the concept of being watched by God (Shariff \& Norenzayan, 2007) and their kindness and percipience toward the deprived life of human beings accompanied by their concept of "Brotherhood" and "Human rights" (Haqooq-ul-ebad) in Islam due to which humanism factor force strongly to contribute for the betterment of society, therefore, the more the factor of humanism the more the participation toward social activity (Horodecka \& Martowska, 2014).

It is also identified that ethics plays an important role to increase humanism (Pless et al. 2017) similarly, the higher the ethical-moral accompanied by spiritual satisfaction the more the social participation that can be seen in Pakistan that people actively give donations and charity for the welfare of humanity whenever they are requested to do, they willfully participate as far as they could.

This research highlights the effect of humanism and ethics on prosocial behavior is distinguished by the observation that social activity due to ethics generally triggers when someone asks for service while humanism in an internal voice to provide service that is more influencing than the external voice of ethics. The empirical result statistically shows the same observed phenomenon representing the coefficient of humanism is more than the coefficient of ethics this shows that people are willfully involved in such activities by themselves for the welfare of human beings to get spiritual satisfaction than to participate on request due to the factor of ethics.

Moreover, this study also reflects that the coefficient of spiritual belief is more than the coefficient of religious belief (Mirza, 2019) that represents the spirituality in people force them to participate more than the people who are contributing due to their religious believes. Although spirituality is directly linked with religiosity strongly most of the time it is also found that people with less religious knowledge found more spiritual and involved in uplifting the less privileged ones.

\section{Conclusion}

The objective of this research was to examine the influence of religiosity and spirituality on prosocial behavior with the role of humanism and ethics as a mediator. The survey was made that shows most of the respondents were male and the rest of them were females who were working in the middle and upper-level management in the public and private establishments of Pakistan. Based on 356 responses we examined that most of the respondents were between 20 
to 30 years of age. These responses were analyzed by using SmartPLS3 to verify the hypothesis for the direct and indirect relationship between the variables. We observe that the result calculated in this study is consistent with the result of other studies while also contradict the result of some studies in many respects that was studied before conducting this research.

In conclusion, religiosity has a direct impact on prosocial behavior while spirituality affects indirectly through mediators i.e. humanism and ethics but the coefficient of spirituality found greater than religiosity this is because of the little difference between the concept of religiosity and spirituality. Spirituality is the backbone of religion and to get Gods' blessing and satisfaction is the most central function for people who find the holiness in whole life. Therefore, we have introduced the perception that religion is a wider construct than spirituality. Religiosity and spirituality are considered similar by many people but most of them understand it in a reverse concept (Zinnbauer et al., 1997). The psychology of religion in terms of differentiation says religion is a broader construct it encircles the finding of many objects of considerations while spirituality only focuses on the specific object of significance i.e. the holiness. Similarly, humanism and ethics' effects on prosocial behavior are differentiated by means of the inner voice and external voice respectively and the impact of the inner voice is stronger to initiate social activity that is proved by the empirical result of this study. The findings suggest that when spirituality motivates people for the social activity they don't consider the religious difference of other people before helping while social activity out of religiosity take some sort of religious similarities of other people into account first but it doesn't mean that other religious community neglect or are ignored due to religion difference.

\section{Limitations \& Recommendations}

This study is limited to upper and middle-level employees most of them were young and less than 30 years of age at which individuals are used to spending more than saving at older age results may differ because the priority changes and the chances of saving may increase that may affect their social activity. Low-level employees are not included in this research that can also affect the result as they get a low income and possibly may found less willing to help in terms of money however, in the non-monetary way the outcome will differ. Data is limited to well-performing organizations of Karachi. Furthermore, this study is required to calculate the identified factors effectively in the model and then presents a more comprehensive framework by examining and integrating all other seemingly relevant factors that affect the society in today's' changing and multi-religious surroundings. Other predictors of religiosity and spirituality may be applied. We hope, discoveries from this research will generate further interest in this topic of research.

\section{References}

Ahmed, A. M., \& Salas, O. (2008). In the back of your mind: Subliminal influences of religious concepts on prosocial behavior. rapport nr.: Working Papers in Economics 331.

Ashmos, D. P., \& Duchon, D. (2000). Spirituality at work: A conceptualization and measure. Journal of management inquiry, 9(2), 134-145. https://doi.org/10.1177/105649260092008

Bhunia, A., \& Mukhuti, S. S. (2011). Workplace Spirituality on Motivations for Earnings Management-An Empirical Analysis. Business management dynamics, 1(4), 73. 
Breaugh, J., Ritz, A., \& Alfes, K. (2017). Work motivation and public service motivation: disentangling varieties of motivation and job satisfaction. public management review, 20(10), 1423-1443. https://doi.org/10.1080/14719037.2017.1400580

Carmines, E. G., \& Zeller, R. A. (1979). Reliability and validity assessment, 17. Sage publications. https://doi.org/10.4135/9781412985642

Einolf, C. J. (2013). Daily spiritual experiences and prosocial behavior. Social indicators research, 110(1), 71-87. https://doi.org/10.1007/s11205-011-9917-3

Eisenberg, N., \& Mussen, P. H. (1989). The roots of prosocial behavior in children. Cambridge university press. https://doi.org/10.1017/CBO9780511571121

Fernando, M., \& Jackson, B. (2006). The influence of religion-based workplace spirituality on business leaders' decision-making: An inter-faith study. Journal of management \& organization, 12 (1), 23-39. https://doi.org/10.1017/S1833367200004144

Fornell, C., \& Larcker, D. F. (1981). Evaluating structural equation models with unobservable variables and measurement error. Journal of marketing research, 18(1), 39-50. https://doi.org/10.1177/002224378101800104

Fry, L.W. (2003) Toward a theory of spiritual leadership. The leadership quarterly, 14(6), 693-727. https://doi.org/10.1016/j.leaqua.2003.09.001

Garson, G. D. (2016). Partial least squares: Regression and structural equation models. Asheboro, NC: Statistical associate publishers.

Ghazzawi, I. A., Smith, Y., \& Cao, Y. (2016). Faith and job satisfaction: Is religion a missing link?. Journal of organizational culture, communications, and conflict, 20(1), 1.

Grant, A. M. (2007). Relational job design and the motivation to make a prosocial difference. Academy of management review, 32(2), 393-417. https://doi.org/10.5465/AMR.2007.24351328.

Grant, A. M. (2012). Leading with meaning: Beneficiary contact, prosocial impact, and the performance effects of transformational leadership. Academy of management journal, 55(2), 458-476. https://doi.org/10.5465/amj.2010.0588.

Grant, A. M., \& Gino, F. (2010). A little thanks goes a long way: Explaining why gratitude expressions motivate prosocial behavior. Journal of personality and social psychology, 98(6), 946. https://doi.org/10.1037/a0017935

Grant, A. M., \& Patil, S. V. (2012). Challenging the norm of self-interest: Minority influence and transitions to helping norms in work units. Academy of management review, 37(4), 547-568. https://doi.org/10. 5465/amr.2010.0437.

Greene, G., \& D'Arcy, J. (2010). Assessing the impact of security culture and the employee-organization relationship on IS security compliance. In the 5th Annual symposium on information assurance, 1-8.

Haenlein, M., \& Kaplan, A. M. (2004). A beginner's guide to partial least squares analysis. Understanding statistics, 3(4), 283-297. https://doi.org/10.1207/s15328031us0304_4

Hair Jr, J. F., Hult, G. T. M., Ringle, C., and Sarstedt, M. (2016). A primer on partial least squares structural equation modeling (PLS-SEM). Sage publications. https://doi.org/10.15358/9783800653614 
Hair Jr, J. F., Matthews, L. M., Matthews, R. L., \& Sarstedt, M. (2017). PLS-SEM or CB-SEM: updated guidelines on which method to use. International journal of multivariate data analysis, 1(2), 107-123. https://doi.org/10.1504/IJMDA.2017.087624

Hardt, J., Schultz, S., Xander, C., Becker, G., \& Dragan, M. (2012). The spirituality questionnaire: Core dimensions of spirituality. Psychology, 3(01), 116. https://doi.org/10.4236/psych.2012.31017

Hoorn, J. V., Dijk, E. V., Meuwese, R., Rieffe, C., \& Crone, E. A. (2014). Peer influence on prosocial behavior in adolescence. Journal of research on adolescence, 26(1), 90-100. DOI:10.1111/jora.12173

Horodecka, A., \& Martowska, K. (2014). Humanistic vision of man: Hope for success, emotional intelligence, and pro-social engagement. International journal of arts and sciences, $6(2), 151-166$.

Huiyuan Jia, R. Z. (2020). Helping others makes me fit better: The effects of helping behavior. Journal of business and psychology. Retrieved from https://link.springer.com/article/10.1007/s10869-020-09680-w

Joseph, S., \& DiDuca, D. (2007). The dimensions of religiosity scale: 20-item self-report measure of religious preoccupation, guidance, conviction, and emotional involvement. Mental health, religion, and culture, 10(6), 603-608. https://doi.org/10.1080/13674670601050295

King, J. E., \& Crowther, M. R. (2004). The measurement of religiosity and spirituality. Journal of organizational change management, 17(1), 83-101. https://doi.org/10.1108/09534810410511314

King, S. M. (2007). Religion, spirituality, and the workplace: Challenges for public administration. Public administration review, 67(1), 103-114. https://doi.org/10.1111/j.1540-6210.2006.00700.x

Klein, N. (2017). Prosocial behavior increases perceptions of meaning in life. The journal of positive psychology, 12(4), 354-361. https://doi.org/10.1080/17439760.2016.1209541

Kline, R., Bankert, A., Levitan, L., \& Kraft, P. (2017). Personality and prosocial behavior: A multilevel meta-analysis. Political science research and methods, 7(1), 125-142. https://doi.org/10.1017/psrm.2017.14

Kock, N., Lynn, G. S. (2012). Lateral collinearity and misleading results in variance-based sem: An illustration and recommendations. Journal of the association for information systems, 13(7), 546-580. https://doi.org/10.17705/1jais.00302

Krause, N., \& Hayward, R. D. (2014). Religious involvement, helping others, and psychological well-being. Mental health, religion \& culture, 17(6), 629-640. https://doi.org/10.1080/13674676.2014.886674

Lambert, N. M., Fincham, F. D., Braithwaite, S. R., Graham, S. M., \& Beach, S. R. (2009). Can prayer increase gratitude?. Psychology of religion and spirituality, 1(3), 139. https://doi.org/10.1037/a0016731 
Li, K. K., \& Chow, W. Y. (2015). Religiosity/spirituality and prosocial behaviors among Chinese Christian adolescents: The mediating role of values and gratitude. Psychology of religion and spirituality, 7(2), 150. https://doi.org/10.1037/a0038294

Lowery, C. M., Duesing, R. J. \& Beadles, N. A. (2014). A research note on the relationships among spirituality, contextual variables, and perceptions of ethics in the workplace. Journal of managerial issues, 408-423.

Malhotra, D. (2010). (When) are religious people nicer? Religious salience and the 'Sunday Effect' on pro-social behavior. Judgment and decision making, 5(2), 138-143.

Marsh, A. A., Kozak, M. N., \& Ambady, N. (2007). Accurate identification of fear facial expressions predicts prosocial behavior. Emotion, 7(2), 239. https://doi.org/10.1037/1528-3542.7.2.239

McCormick, D.W. (1994). Spirituality and management. Journal of managerial psychology, 9(6), 5-8. https://doi.org/10.1108/02683949410070142

McLaughlin, C. (2009) Spiritual politics: Changing the world from the inside out. Ballantine books, New York.

Meng, Y. (2016). Spiritual leadership at the workplace: Perspectives and theories. Biomedical reports, 5(4), 408-412. DOI:10.3892/br.2016.748.

Mirza, M., \& Siddiqui, D.A. (2019). The best of both worlds: Establishing linkages between spirituality and religiosity on strategic decision making with the mediating role of empathy. https://doi.org/10.2139/ssrn.3444138

Omoto, A. M., Snyder, M., \& Berghuis, J. P. (1993). The psychology of volunteerism: A conceptual analysis and a program of action research. In J. B. Pryor \& G. D. Reeder (Eds.), The social psychology of HIV infection (p. 333-356). Lawrence Erlbaum Associates, Inc.

Osman-Gani, A. M., Hashim, J., \& Ismail, Y. (2013). Establishing linkages between religiosity and spirituality on employee performance. Employee relations. https://doi.org/10.1108/ER-04-2012-0030

Oviedo, L. (2016). Religious attitudes and prosocial behavior: A systematic review of published research. Religion, brain \& behavior, 6(2), 169-184. https://doi.org/10.1080/2153599X.2014.992803

Pargament, K.I. (1999). The psychology of religion and spirituality: Yes and no. The International journal for the psychology of religion, $9(\mathrm{I})$, 3-16. https://doi.org/10.1207/s15327582ijpr0901_2

Park, J. Z., \& Smith, C. (2000). 'To whom much has been given...': Religious capital and community voluntarism among churchgoing protestants. Journal for the scientific study of religion, 39(3), 272-286. https://doi.org/10.1111/0021-8294.00023

Parrish, M. (2014). Social work perspectives on human behavior. Maidenhead berkshire, England: Open university press.

Patel, M. R., \& Selvaraj, P. (2015). Role of socio-cultural factors in the entrepreneurial success of the Jain community. International journal of Indian culture and business management, 10(3), 291-305. https://doi.org/10.1504/IJICBM.2015.068487 
Piff, P. K., Kraus, M. W., Côté, S., Cheng, B. H., \& Keltner, D. (2010). Having less, giving more: The influence of social class on prosocial behavior. Journal of personality and social psychology, 99(5), 771-784. https://doi.org/10.1037/a0020092

Pless, N. M., Maak, T., \& Harris, H. (2017). Art, ethics, and the promotion of human dignity. Journal of business ethics, 144(2), 223-232. https://doi.org/10.1007/s10551-017-3467-9

Possumah, B. T., Ismail, A. G., \& Shahimi, S. (2013). Bringing work back in Islamic ethics. Journal of business ethics, 112(2), 257-270. https://doi.org/10.1007/s10551-012-1246-1

Preston, J. L., Salomon, E., \& Ritter, R. S. (2013). Religious prosociality: Personal, cognitive, and social factors. In religion, personality, and social behavior, 149-169. Taylor and Francis. https://doi.org/10.4324/9780203125359

Raposa, E. B., Laws, H. B., \& Ansell, E. B. (2015). Prosocial behavior mitigates the negative effects of stress in everyday life. Clinical psychological science, 4(4), 691-698. https://doi.org/10.1177/2167702615611073

Ringle, C. M., Wende, S., \& Becker, J. M. (2015). Smartpls 3. Bonningstedt: SmartPLS. Retrieved from http://smartpls.com.

Salehzadeh, R., Pool, J. K., Lashaki, J. K., Dolati, H., \& Jamkhaneh, H. B. (2015). Studying the effect of spiritual leadership on organizational performance: An empirical study in hotel industry. International journal of culture, tourism and hospitality research. https://doi.org/10.1108/IJCTHR-03-2015-0012

Saroglou, V. (2013). Religion, spirituality, and altruism. In K. I. Pargament, J. Exline, \& J. Jones (Eds.), APA Handbook of psychology, religion, and spirituality, 1, 439-457. Washington, DC: American psychological association. https://doi.org/10.1037/14045-024

Sarstedt, M., \& Cheah, J. H. (2019). Partial least squares structural equation modeling using SmartPLS: A software review. Journal of marketing analytics, 7(3), 196-202. https://doi.org/10.1057/s41270-019-00058-3

Shariff, A. F., \& Norenzayan, A. (2007). God is watching you: Priming God concepts increases prosocial behavior in an anonymous economic game. Psychological science, 18(9), 803-809. https://doi.org/10.1111/j.1467-9280.2007.01983.x

Sharma, S. K., Rastogi, R., \& Garg, P. (2013). Workplace spirituality and managerial effectiveness among Indian managers. International journal of indian culture and business management, 6(3), 382-390. https://doi.org/10.1504/IJICBM.2013.053109

Shinde, U., \& Fleck, E. (2015). What spirituality can bring to leaders and managers: Enabling creativity, empathy and a stress free workplace. Journal of organizational psychology, 15(1), 101.

Small, D. A., \& Simonsohn, U. (2007). Friends of victims: Personal experience and prosocial behavior. Journal of consumer research. https://doi.org/10.2139/ssrn.850108

Survey of online fundraisers, (n.d). Sponsors, and donors, summary of responses. Retrieved from http://www.bristol.ac.uk/media-library/sites/cmpo/migrated/documents/jgsurvey.pdf Umbreit, M. S. (1997). Humanistic mediation: A transformative journey of peacemaking. Mediation quarterly, 14(3), 201-213. https://doi.org/10.1002/crq.3900140305 
Usman, A. H., Shaharuddin, S. A., \& Abidin, S. Z. (2017). Humanism in islamic education: Indonesian references. International journal of asia-pacific studies, 13(1).

Van Cappellen, P., \& Rimé, B. (2014). Positive emotions and self-transcendence. In V. Saroglou (Ed.), Religion, personality, and social behavior, 123-146. New York, NY: Psychology press.

Verma, P., \& Singh, A. (2016). The impact of religiosity upon managers' CSR orientation: An empirical study in the Indian perspective. International journal of indian culture and business management, 12(4), 407-424.

Wuthnow, R. (1994). Sharing the journey: Support groups and America's new quest for community. Free Press.

Xiaoming, H. U. (2001). Oriental physical education and sport need humanism. sports \& science, 1(003).

Zimmer, Z., Jagger, C., Chiu, C. T., Ofstedal, M. B., Rojo, F., \& Saito, Y. (2016). Spirituality, religiosity, aging, and health from a global perspective: A review. SSM-population health, 2, 373-381. https://doi.org/10.1016/j.ssmph.2016.04.009

Zinnbauer, B. J., Pargament, K. I., Cole, B., Rye, M. S., Butter, E. M., Belavich, T. G., ... \& Kadar, J. L. (1997). Religion and spirituality: Unfuzzying the fuzzy. Journal for the scientific study of religion, 549-564. https://doi.org/10.2307/1387689

Zwingmann, C., Klein, C., \& Büssing, A. (2011). Measuring religiosity/spirituality: Theoretical differentiations and categorization of instruments. Religions, 2(3), 345-357. https://doi.org/10.3390/rel2030345

\section{Copyright Disclaimer}

Copyright reserved by the author(s).

This article is an open-access article distributed under the terms and conditions of the Creative Commons Attribution license (http://creativecommons.org/licenses/by/4.0/). 